[Agr. Biol. Chem., Vol. 36, No. 13, p. 2555 2561, 1972]

\title{
Isolation of Neutral Growth Inhibitors in Dwarf Peas ${ }^{\dagger}$
}

\author{
By Nobuo Komoto,* Masana Noma,** Susumu IKegamI \\ and Saburo TAmura \\ Department of Agricultural Chemistry, The University of Tokyo, \\ Bunkyo-ku, Tokyo
}

Received August 10, 1972

\begin{abstract}
From seedlings of dwarf pea (Pisum sativum L., var. Progress No. 9) grown under red light, three neutral growth inhibitors were isolated which interfered with the responses of these plants to $\mathrm{GA}_{3}$. The compounds were identified as $\beta$-sitosterol, $\alpha$-stearoyl glycerol and pisatin, of which the glyceride produced remarkable inhibition when applied to terminal buds. Though its anti-gibberellin activity was not very strong, pisatin produced inhibition of the straightgrowth of Avena coleoptile segments caused by IAA.
\end{abstract}

In 1963 Köhler and Lang $^{11}$ reported that dwarf pea seedlings grown under red light contain substances which reduce the responses of these plants to gibberellin $\mathrm{A}_{3}\left(\mathrm{GA}_{3}\right)$. Following this experiment, we attempted to isolate substances with anti-gibberellin activity from light-grown dwarf peas and separated several acidic growth inhibitors, which were identified as fumaric, palmitic, oleic and abscisic acids and methyl and ethyl hydrogen succinates. ${ }^{21}$

In this paper we wish to report the isolation of $\alpha$-stearoyl gycerol, $\beta$-sitosterol and pisatin as neutral growth inhibitors from the same plant materials, as well as the biological activities of these compounds. Of the neutral inhibitors, $\alpha$-stearoyl glycerol was found the most effective, its inhibitory activity on the stem growth of dwarf peaks being far stronger than that of pisatin which was previously suggested as the main principle in the neutral fraction. ${ }^{3}$

Until now, pisatin has been considered to be

+ Occurrence of Substances in Dwarf Peas Interfering with the Responses of these Plants to Gibberellin, Part II. Part I., see reference 2).

* Present address: Research Center, MitsuiToatsu Chemicals Incorp., Kasama-cho, Totsuka-ku, Yokohama.

** Present address: Central Research Institute, Japan Monopoly Corporation, Shinagawa-ku, Tokyo. a phytoalexin formed as a response to innoculation of the pea pod endocarp tissues with fungi.") Through our experiment, however, this compounds was demonstrated to be a normal constituent of dwarf pea seedlings. The time-course of changes in the content of pisatin at the earlier growth stage of the seedlings was also examined.

\section{MATERIALS AND METHODS}

Plant materials. Seedlings of dwarf pea (Pisum sativum L., var. Progress No. 9) were cultivated in the same way as described in the preceding paper. ${ }^{23}$ To separate $\alpha$-stearoyl glycerol and $\beta$-sitosterol, plant materials which had previously undergone the extraction procedure for acidic inhibitors were utilized.

Dwarf pea bioassay. Inhibitory activity on the stem growth of dwarf pea seedlings was assayed in the presence or absence of $G_{3} A_{3}$ according to the procedure described earlier."

Avena colcoptile straightgrowth bioassay. Inhibitory effect on the straight-growth of Avena coleoptile segments caused by indoleacetic acid (IAA) was assayed according to the method of Nitsch and Nitsch. ${ }^{51}$

Thin-layer chromatography. Thin-layer chromatography (TIC) was conducted on Kieselgel GF $\mathrm{F}_{254}$ plates of $0.25 \mathrm{~mm}$ thickness. Solvent systems employed here were as follows: $n$-hexane-acetone-toluene 
(50:35:15, Solvent 1), chloroform-methanol (95:5, Solvent 2), chloroform-methanol-acetic acid-water (90:8:1:1, Solvent 3), chloroform-ethyl acetate $(6: 4$, Solvent 4), and isopropyl ether-acetic acid (95:5, Solvent 5).

Inhibitory substances on the plates were detected by spraying $1 \%(\mathrm{w} / \mathrm{v})$ potassium permanganate in ethanol or by irradiating with UV light at $254 \mathrm{~m} \mu$.

Spectral meastrements. IR spectra were obtained with a JASCO IR-S spectrometer. UV spectra were obtained with a Cary 14 spectrophotometer. NMR spectra were recorded on a JEOL-JNM-4H spectrometer at $100 \mathrm{MHz}$ with tetramethylsilane as an internal standard. Mass spectra were measured with a Hitachi RMU-6L mass spectrometer operated at an ionization energy of $70 \mathrm{eV}$.

Chemicals, Authentic samples of $\alpha$-stearoyl glycerol and $\beta$-sitosterol were purchased from commercial suppliers and were purified by TLC, using Solvent 2 for the former and Solvent 4 for the latter.

\section{RESULTS AND DISCUSSION}

I. Fractionation of inhibitory substances in the neutral fraction

a) Isolation of $\beta$-sitosterol and $\alpha$-stearoyl glyecrol. The procedure for the isolation of $\beta$-sitosterol and $\alpha$-stearoyl glycerol is shown in Fig. 1. Dwarf pea seedlings $(66 \mathrm{~kg}$, fresh weight) grown for 9 days under red light were extracted with two 200 liter-portions of methanol. After evaporation of the solvent, the aqueous residue ( 30 liters) was adjusted to pH 3.0 with dil. hydrochloric acid and extracted with two 20 liter-portions of ethyl acetate. The combined extracts were shaken with two 15 liter-portions of saturated sodium bicarbonate solution to remove the acidic fraction. The organic layer, containing the neutral fraction, was washed with saturated sodium bicarbonate solution, dil. hydrochloric acid and water, successively. After drying over anhydrous sodium sulfate, the solvent was removed under reduced pressure to give a dark-brown syrup (55 g).

* The numerals in parentheses show the $v / v$ ratios.
The syrup $(10 \mathrm{~g})$ was dissolved in a small volume of benzene and applied to a silica gel column $(200 \mathrm{~g}, 5 \times 25 \mathrm{~cm})$, which was eluted with 1 liter each of benzene and benzene-ethyl acetate, increasing the concentration of the latter stepwise by $10 \%(\mathrm{v} / \mathrm{v})$ from 10 to $100 \%$. An aliquot taken from each eluate was evaporated to dryness and subjected to dwarf pea bioassay. Eluates with benzene alone and benzene containing $10 \sim 20 \%$ ethyl acetate, which revealed biological activity, were separately evaporated to dryness.

The solid $(6.3 \mathrm{~g})$ obtained from the benzene fraction was repeatedly recrystallized from methanol to yield colorless needles (320 mg, Substance A), which were identified later as $\beta$-sitosterol.

The solid $(1.1 \mathrm{~g})$ from the $10 \sim 20 \%$ ethyl acetate fraction was again applied to a silica gel column $(20 \mathrm{~g}, 1 \times 60 \mathrm{~cm})$ and was developed with benzene-ethyl acetate $(9: 1, v / v)$, collecting $8 \mathrm{ml}$ portions of eluate. Fractions No. 11 25 , showing biological activity, were combined and evaporated to afford a semi-solid. Recrystallization from methanol yielded colorless flakes (14 mg, Substance B), which were identified later as $\alpha$-stearoyl glycerol.

b) Isolation of pisatin.* Dwarf pea seedlings $(155 \mathrm{~kg}$, fresh weight) were extracted with methanol in the same manner described above. After evaporation of the solvent, the aqueous residue was repeatedly extracted with $n$-butyl acetate, which was then evaporated. The residual syrup was partitioned between $n$ hexane and 90\% aqueous methanol. The methanol phase was separated and evaporated, and the aqueous residue was extracted with diethyl ether by means of a continuous extractor. The extract was dried over anhydrous sodium sulfate and evaporated to give a brown syrup $(29 \mathrm{~g})$. The syrup was applied

* Since we did not anticipate the formation of pisatin in healthy dwarf peas, we adopted a rather tedious procedure for the isolation of this compound. 


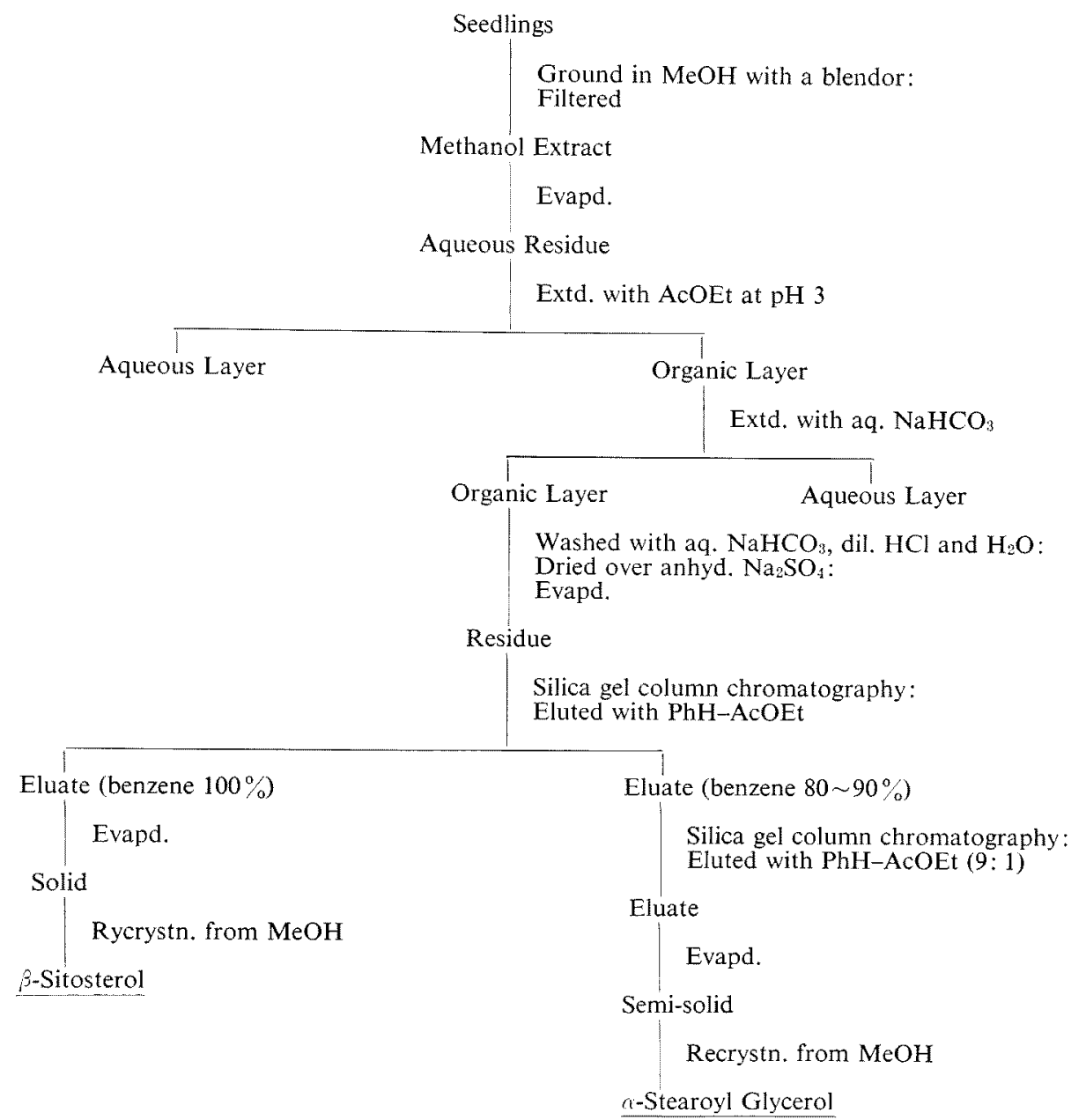

FIG. 1. Procedure for the Isolation of $\beta$-Sitosterol and $\alpha$-Stearyl Glycerol from Dwarf Pea Seedlings.

to a charcoal column (Wako, $300 \mathrm{~g}, 932 \mathrm{~cm}$ ), which was developed with 3 liters each of acetone-water, increasing the concentration of the former by $10 \%(\mathrm{v} / \mathrm{v})$ stepwise from 10 to $100 \%$. The eluate with $80 \%$ aqueous acetone, showing biological activity, was evaporated to dryness.

The residue $(18 \mathrm{~g})$ was applied to an alumina column $(200 \mathrm{~g}, 4.5 \times 17 \mathrm{~cm})$, which was eluted with benzene-ethyl acetate $(9: 1, v / v)$. Combined active fractions were evaporated to give a solid $(7.7 \mathrm{~g})$ and were charged onto a silica gel column $(100 \mathrm{~g}, 4.5 \times 14 \mathrm{~cm})$. Elution with benzene-ethyl acetate $(9: 1, \mathrm{v} / \mathrm{v})$ yielded active fractions, which, on evaporation, gave a solid $(3.5 \mathrm{~g})$. The solid was rechromatographed in the same way. The white powder $(1.7 \mathrm{~g})$ thus obtained was subjected to preparative TLC on Kieselgel $G_{254}$ plates with Solvent 1. The zone at $R f 0.4 \sim 0.6$, showing biological activity, was extracted with ethyl acetate. After evaporation of the solvent, the residual solid was repeatedly crystallized from methanol to afford colorless fine needles $(15 \mathrm{mg}$, Substance 
C), identified as pisatin, as described later.

\section{Characterization and identification of $\beta$ -} sitosterol

Substance A melted at $137 \sim 139^{\circ} \mathrm{C} .^{* *}$ It showed a single spot with $\mathrm{KMnO}_{4}$ spray on TLC using Solvent 2 ( Rf 0.46$)$ or $3(R f 0.75)$. The steroidal nature of the substance was suggested by positive coloration with the Liebermann-Buchard ${ }^{6}$ and Salkowski ${ }^{7}$ reagents, IR $\nu_{m ; x}^{\text {Nujol }} \mathrm{cm}^{-1}: 3425,1660,1640$, 840, 810. NMR $\delta_{3 e_{4} \mathrm{Sl}}^{\mathrm{CDCl}_{3}}: 0.68(3 \mathrm{H}, \mathrm{s}), 0.80$ $(3 \mathrm{H}, \mathrm{s}), 0.87(6 \mathrm{H}, \mathrm{d}), 0.96(3 \mathrm{H}, \mathrm{s}), 1.01(3 \mathrm{H}, \mathrm{s})$, 3.54 (1H, bs), $5.31(1 \mathrm{H}, \mathrm{d})$. MS m/e: 414 $\left(\mathrm{M}^{+}\right), 399\left(\mathrm{M}^{+}-\mathrm{CH}_{3}\right), 396\left(\mathrm{M}^{+}-\mathrm{H}_{2} \mathrm{O}\right), 231$ (D ring fission), 213 (D ring fission and dehydration), 145 (C ring fission). These spectral data were identical with those of $\beta$-sitosterol.

Substance $A$ and an authentic sample of $\hat{\beta}$ sitosterol showed identical $R f$ values on TLC with Solvent 2 or 3 . Further, the $\mathrm{mp}$ of Substance A showed no depression on admixture with the authentic specimen.

\section{Characterization and identification of $\alpha$ - stearoyl glycerol}

Substance B, mp $78 \sim 80^{\circ} \mathrm{C}$, showed a single spot with $\mathrm{KMnO}_{4}$ spray on TLC using Solvent $4(R f 0.39)$ or $5(R f 0.50)$. IR $\nu_{\mathrm{m} i \mathrm{x}}^{\mathrm{Nujo1}} \mathrm{cm}^{-1}$ : $3320 \sim 3250,1735,1195,1180,1100,1045$. NMR $o_{\mathrm{Me}_{4} \mathrm{si}}^{\mathrm{CDCl}}: 0.88(3 \mathrm{H}, t), \quad 1.25(30 \mathrm{H}, \mathrm{s})$, $2.35(2 \mathrm{H}, \mathrm{t}), 2.85(2 \mathrm{H}, \mathrm{bs}), 3.62(2 \mathrm{H}, \mathrm{d}), 3.80$ $(1 \mathrm{H}, \mathrm{m}), 4.16(2 \mathrm{H}, \mathrm{d})$.

On treatment with acetic anhydride in pyridine at room temperature for $24 \mathrm{hr}$, Substance $\mathrm{B}$ afforded a diacetate. NMR $\sigma_{\mathrm{Mo}_{4} \mathrm{Si}}^{\mathrm{CDCl}_{3}}: 0.88$ $(3 \mathrm{H}, \mathrm{t}), 1.26(30 \mathrm{H}, \mathrm{s}), 2.34(2 \mathrm{H}, \mathrm{t}), 4.20(4 \mathrm{H}$, dd), 5.22-5.38 (1H, sextet).

\footnotetext{
* On the basis of the data obtained later by chemical assay, $155 \mathrm{~kg}$ of dwarf pea seedlings grown under red light for 9 days are assumed to contain approximately $3 \mathrm{~g}$ of pisatin.

** Throughout this study melting points were determined on a microscope hot stage and are uncorrected.
}

Although the molecular ion peak was not observed in the mass spectrum of Substance $\mathbf{B}$, the appearance of the base peak at $m / e 239$, as well as of peaks due to characteristic fragmentation of a long-chain fatty acid moiety, strongly suggested that the compound was some kind of glyceride. The NMR spectrum of Substance B was identical with that of an authentic sample of $\alpha$-stearoyl glycerol. Further, both specimens showed identical $R f$ values on TLC using Solvent 4 or 5.

\section{Characterization and identification of pisatin}

Substance $\mathrm{C}$ showed a single spot on TLC with Solvent 1 ( $R f$ 0.50) and $\mathrm{KMnO}_{4}$ spray. $\mathrm{Mp} 69 \sim 71^{\circ} \mathrm{C}$. UV $\lambda_{\mathrm{m} \text { : }}^{\mathrm{E} \text { to }} \mathrm{m} \mu(\varepsilon): 309(3.86)$, 285 (3.68). IR $\nu_{\mathrm{max}}^{\mathrm{Nujol}} \mathrm{cm}^{-1}: 3610,1625,1490$,

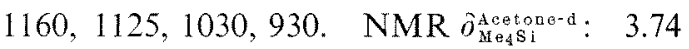
$(3 \mathrm{H}, \mathrm{s}), 4.19(2 \mathrm{H}, \mathrm{s}), 5.27(1 \mathrm{H}, \mathrm{s}), 5.92(2 \mathrm{H}, \mathrm{d})$, $6.36(1 \mathrm{H}, \mathrm{s}), 6.38(1 \mathrm{H}, \mathrm{d}), 6.61(1 \mathrm{H}, \mathrm{dd}), 6.92$ (1 H, s), $7.36(1 \mathrm{H}, \mathrm{d})$.

These data coincide with those for pisatin, 3-hydroxy-7-methoxy-4', 5'-methylenedioxychromanocoumarane, ${ }^{8 /}$ which was first isolated from Pisum sativum L. as a phytoalexin by Cruickshank and Perrin. ${ }^{4}$ Further, Substance $C$ revealed a characteristic shift of UV absorption maxima on treatment with hydrochloric acid at room temperature, suggesting the formation of anhydropisatin, $\lambda_{\max }^{\mathrm{ExOH}} 358$ $\mathrm{m} \mu{ }^{8}$

\section{$V$ Time-course of changes in pisatin con-} tent in dwarf pea seedlings

Until now, the chemical assay of pisatin has been performed by measurement of its characteristic UV absorption at $309 \mathrm{~m} \mu{ }^{4}$ ? In our experiment using pea seedlings, however, some impurities disturbed the measurement at this wave length. After several trials, we discovered that the optical density (OD) at $358 \mathrm{~m} \mu$ of anhydropisatin, which is easily and quantitatively produced from pisatin 
by mild acid treatment, was measurable without any disturbance. The ratio of $\mathrm{OD}_{358}$ to $\mathrm{OD}_{309}$ was 2.01 .

Dwarf pea seedlings $(100 \sim 150 \mathrm{~g})$ grown for various periods of time were harvested and extracted four times with twice their weight of methanol in a blendor. The combined extracts were evaporated under reduced pressure, and, after saturation with sodium bicarbonate, the aqueous residue was extracted four times with twice its volume of ether. The combined extracts were evaporated and shaken with a 1:1 mixture $(100 \mathrm{ml})$ of $n$ hexane and $80 \%$ aqueous methanol. The methanol layer was separated, shaken three times with three $50 \mathrm{ml}$-portions of $n$-hexane, which had been saturated with $80 \%$ aqueous methanol, and evaporated under reduced pressure. The aqueous residue was extracted four times with twice its volume of $n$-hexane, which was then evaporated under reduced pressure. The residue was dissolved in ethanol $(50 \sim 100 \mathrm{ml})$, and the absorbance at $358 \mathrm{~m} \mu$ due to contaminants was measured with this solution. After addition of an equal

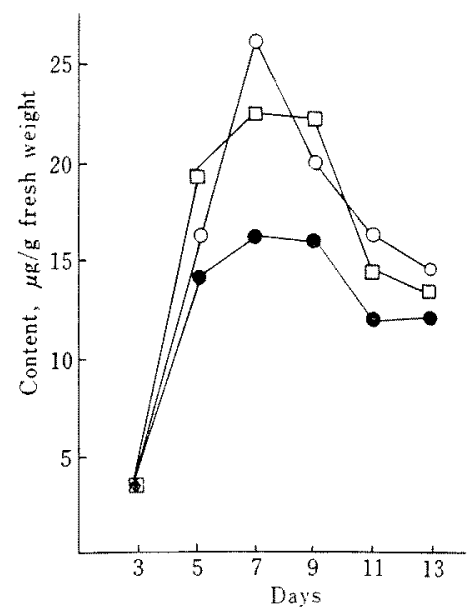

FIG. 2. Time-course of Changes in the Content of Pisatin in Dwarf Pea Seedlings Grown in Red Light, Daylight and Darkness.

$\bigcirc-O$ Red light, - Daylight, $\square-\square$ Darkness. volume of $0.2 \mathrm{~N}$ sulfuric acid, the solution was kept overnight at room temperature. UV measurement was performed again at $358 \mathrm{~m} \mu$ to determine the amount of pisatin.

As indicated in Fig. 2, the pisatin content in dwarf pea seedlings reached a maximum 7 days after germination ( $26 \mu \mathrm{g}$ per $\mathrm{g}$ of fresh seedlings) and rapidly decreased thereafter. Though red light seemed somewhat favorable for pisatin formation, the content decreased to the same level as that under daylight or darkness after 13 days cultivation. In any event, pisatin should be considered as a normal constituent in dwarf peas, nor as a phytoalexin.

\section{Biological activities of neutral growth inhibitors}

At first, the inhibitory effects of $\alpha$-stearoyl glycerol, $\beta$-sitosterol and pisatin were examined on the stem elongation of dwarf pea seedlings in the presence of $0.015 \mu \mathrm{g}$ of $\mathrm{GA}_{3}$. As illustrated in Fig. 3, $\alpha$-stearoyl glycerol re-

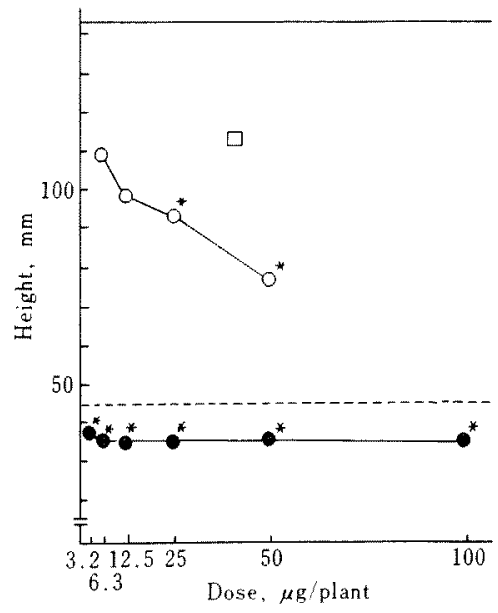

FIG. 3. Inhibitory Effects of $\beta$-Sitosterol, $\alpha$-Stearoyl glycerol and Pisatin on the Stem Growth of Dwarf Pea Seedlings in the Presence of $\mathrm{GA}_{3}(0.015 \mu \mathrm{g})$.

$\bigcirc-0 \quad \beta$-Sitosterol, - $\alpha$-Stearoyl glycerol, $\square-\square$ Pisatin, - Control (with $\mathrm{GA}_{3}, 0.015 \mu \mathrm{g}$ ), -.-.- Control (without $\mathrm{GA}_{3}$ ), * Shows Appearance of injury. 
vealed striking activity. Even at a dose of $1.0 \%$ per plant, it produced $100 \%$ inhibition of the response of seedlings to $\mathrm{GA}_{3}$. On the other hand, anti-gibberellin activity of $\beta$ sitosterol and pisatin was not very strong: the former showed $50 \%$ inhibition at a dose of $20 \mu \mathrm{g}$ per plant and the latter showed $30 \%$ inhibition at $40 \mu \mathrm{g}$.

When assayed in the absence of $\mathrm{GA}_{3}, \beta$ sitosterol and pisatin revealed hardly any inhibitory activity on the stem growth of dwarf peas. $\alpha$-Stearoyl glycerol showed strong inhibition even at a dose of $0.5 \mu \mathrm{g}$ per plant, and the extent of inhibition caused by this compound did not vary at doses ranging from 1.0 to $50 \mu \mathrm{g}$. The results are shown in Fig. 4 .

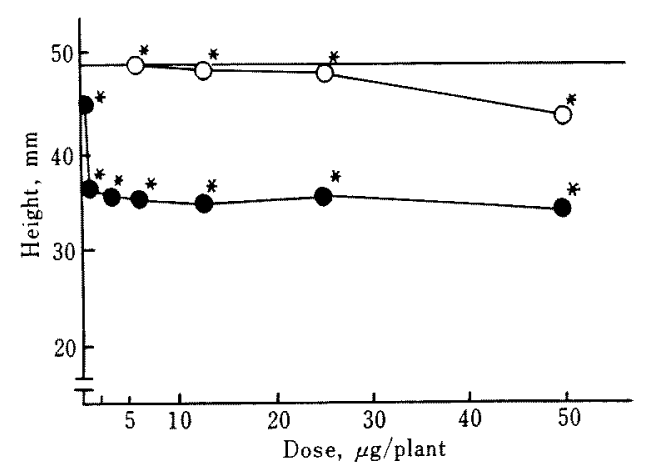

FIG. 4. Inhibitory Effects of $\beta$-Sitosterol and $\alpha$ Stearoyl glycerol on the Stem Growth of Dwarf Pea Seedlings in the Absence of $\mathrm{GA}_{3}$.

$\bigcirc-\bigcirc \beta$-Sitosterol, - $\alpha$-Stearyl glycerol, _ Control, * Shows appearance of injury.

Irrespective of the presence of $\mathrm{GA}_{3}$, the application of $\alpha$-stearoyl glycerol caused rapid chlorosis on apical buds within a few hr, followed by final necrosis. However, the injury was restricted to the part where the compound was applied, and each seedling began to develop a new bud at the base of the hypocotyl. Interestingly, no growth inhibition was observed when dwarf peas were cultivated in water containing the mono- glyceride. Further, it did not produce inhibitory effects on the growth of rice and lettuce seedlings which were grown on filter papers moistened with water containing the chemical at a concentration of $1000 \mathrm{mg}$ per liter.

In the Avena straight-growth test, $\beta$-sitosterol and $\alpha$-stearoyl glycerol did not counteract the elongation of segments caused by IAA at a concentration of $1 \mathrm{mg}$ per liter. On the other hand, pisatin at $50 \mathrm{mg}$ per liter produced $60 \%$ inhibition, as shown in Fig. 5.

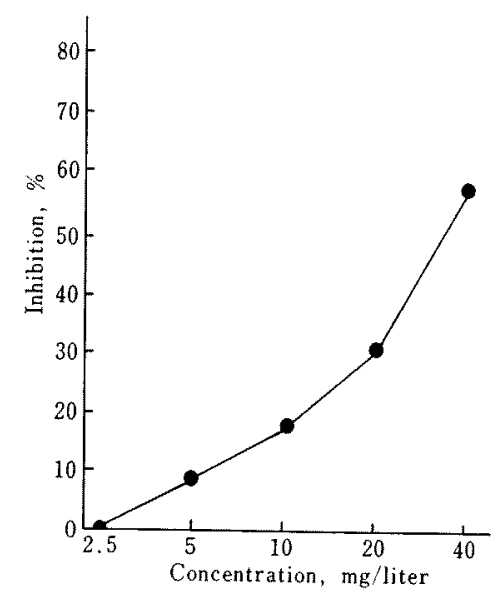

FIG. 5. Inhibitory Effect of Pisatin on the Growth Response of Avena Coleoptile Segments to IAA (1 mg/liter).

As in the case of the acidic inhibitors mentioned earlier, ${ }^{2}$ no correlation was observed between the level of neutral inhibitors in dwarf peas and the light level during cultivation. The presence of light-dependent inhibitors must be further investigated in dwarf pea seedlings.

Acknowledgement. We thank Mr. K. Aizawa of this Department for the spectral measurements.

\section{REFERENCES}

1) D. Köhler and A. Lang, Plant Physiol., 38, 555 (1963). 
2) N. Komoto, S. Ikegami and S. Tamura, Agr. Biol. Chem., the preceding paper.

3) S. Tamura, S. Ikegami, N. Komoto and M. Noma, "Plant Growth Substances 1970," ed. by D. J. Carr, Springer-Verlag, Berlin, 1972, p. 306.

4) I. A. M. Cruickshank and D. R. Perrin, Nature, 187, 799 (1960); Aust. J. Biol. Sci., 14, 336 (1961).
5) J.P. Nitsch and C. Nitsch, Plant Physiol., 31, 94 (1956).

6) D. R. Idler and C. A. Baumann, J. Biol. Chem., 203, 389 (1953).

7) E. Salkowski, Z. Physiol. Chem., 57, 523 (1908).

8) D. R. Perrin and W. Bottomley, J. Am. Chem. Soc., 84, 1919 (1962). 